\title{
The impact of new regulations on the incidence and severity of ocular injury sustained in hurling
}

MI Khan', T Flynn², E O'Connell'1, J Stack ${ }^{3}$ and S Beatty ${ }^{1}$

\section{Abstract}

Aim To prospectively evaluate, and compare, the incidence of hurling-related eye injuries in the South East of Ireland before and after implementation of new rules rendering the use of protective head gear and face masks compulsory for players aged 18 years or under. Methods Details relating to patients attending the regional ophthalmic department with injuries sustained during hurling were prospectively recorded between 1 October 2003 and 31 March 2006.

Results Sixty players attended with hurlingrelated ocular injuries during the study period. Of these, $43(71.6 \%)$ and $17(28.3 \%)$ sustained the ocular injuries during the 15-month period before, and after implementation of the new rules (1 January 2005), respectively. Restricting our analysis to players aged 18 years or under, and, for statistical validity, to the 12-month period immediately before and immediately after implementation of the new rules, a statistically significant reduction in the number of hurling-related injuries was seen (1 January 2004 to 31 December 2004: 11; 1 January 2005 to 31 December 2005: $2 ; \chi^{2}$ test $\left.P<0.05\right)$ in this age group. A permanent visual deficit was seen in $11(18.3 \%)$ patients. Of these, one (9\%) was aged 18 years or under, and this injury was sustained before the new regulations.

Conclusion New rules rendering the use of protective eye wear compulsory for players aged 18 years or under have resulted in a significant reduction in the incidence and severity of hurling-related eye injuries in this age group.

Eye (2008) 22, 475-478; doi:10.1038/sj.eye.6702659; published online 1 December 2006

Keywords: hurling; ocular; trauma; injuries; regulations

\section{Introduction}

Hurling is an outdoor team sport of Celtic origin, played with a stick (caman) and a ball (sliotar). The stick, traditionally made from the root of Ash tree, is typically $64-97 \mathrm{~cm}$ in length with a flat face opposite its handle (bas). The ball is made of cork (covered with a leather wound string) and weighs between 100 and $130 \mathrm{~g}$, with a circumference that is between 23 and $25 \mathrm{~cm} .{ }^{1}$ A good strike with a stick can propel the ball up to 93 miles per hour $(150 \mathrm{~km} /$ $\mathrm{h})$, and to a distance of 262 feet $(80 \mathrm{~m}){ }^{2}$

A study conducted at the Departments of Ophthalmology (DoO) of Cork University Hospital, and of Waterford Regional Hospital (WRH) revealed that 310 patients attended these departments with ocular injuries sustained while engaged in hurling between 1 January 1994 and 31 December 2003. Of these, 52 (17\%) required admission for treatment of the ocular trauma, and $10(3.2 \%)$ required surgical intervention, either urgently or electively. Of these 310 ocular injuries, $14(3.2 \%)$ had a final best-corrected visual acuity (BCVA) of $6 / 12$ or less, six (2\%) had a final BCVA of $3 / 60$ or worse (legally blind according to The World Health Organization). ${ }^{3}$

As a result of Flynn et al's $\mathrm{s}^{3}$ findings, reported in the British Journal of Sports Medicine in 2005, the Gaelic Athletic Association (GAA), the regulatory body for hurling, changed the rules and regulations governing this game. From 1 January 2005, it became mandatory for all players aged 18 years or under to wear protective helmets and face masks while engaged in hurling, and from 1 April 2006, this rule was extended to all players aged 21 years or under.

The current study was conducted to investigate the impact of these new regulations
${ }^{1}$ Department of Ophthalmology, Waterford Regional Hospital, Waterford, Ireland

${ }^{2}$ Research Department, Institute of Ophthalmology, University College London, London, UK

${ }^{3}$ Waterford Institute of Technology, Waterford Ireland

Correspondence: MI Khan, Department of Ophthalmology Waterford Regional Hospital,

Waterford,

Co Waterford, Ireland.

Tel: + 35351842378 Fax: + 35351854910 . E-mail:mikaeh@ gmail.com

Received: 8 June 2006 Accepted in revised form: 1 October 2006 Published online: 1 December 2006 
on the incidence and severity of ocular injuries sustained during hurling in the South East of Ireland.

\section{Materials and methods}

All ocular injuries sustained while engaged in hurling, which presented to the Accident and Emergency (A\&E) section of the DoO at WRH, between 1 October 2003 and 31 March 2006 were prospectively studied.

The following data were recorded in each case: demographic data; mechanism of injury (ball, stick, or other); role in game (player, spectator, referee); nature of injury; length of stay in hospital (if any); management; number of follow-up visits; visual outcomes; and the use, or non-use of protective helmet, and face mask when the injury was sustained. Of note, some players wear protective helmets without a face mask, some have tended to modify the face mask by removing one or more bars in an attempt to minimise the perceived negative impact on a player's performance, some wear a protective helmet with an unmodified face mask, and some wear neither helmet nor face mask.

The data were analysed using descriptive statistics, and comparisons were made with respect to the incidence of hurling-related eye injuries sustained before and after implementation of the new rules (rendering the use of protective helmets and face masks compulsory for players aged 18 years or under) using $\chi^{2}$ test and by calculating the $95 \%$ confidence interval (CI) of any observed difference. Of note, and in order to make a valid statistical comparison of the incidence of hurlingrelated eye injuries before and after implementation of the new rule (given the seasonal nature of hurling), the data were restricted to the 12-month period immediately before and immediately after the new rule came into effect.

\section{Results}

Sixty hurling-related eye injuries presented to the A\&E section of the DoO at WRH during the study period (1 October 2003 to 31 March 2006). The male to female ratio was $58: 2(96: 4 \%)$, and the mean age $( \pm \mathrm{SD})$ was 23.8 $( \pm 2)$ years. Of these, $42(70 \%)$ were the result of injury by the ball and 17 (28.3\%) were the result of impact with the stick, whereas one (1.6\%) injury resulted from collision with another player. Sixty $(100 \%)$ of those injured were players, whereas no referees or spectators who sustained hurling-related ocular injury during the study period attended the A\&E section of WRH.

Twenty-one $(35 \%)$ players were wearing protective helmets at the time of injury. Of these, $15(71 \%)$ were wearing helmets with an unmodified face mask, two $(9.5 \%)$ were wearing helmets with a modified face mask and four (19\%) were wearing a helmet without any face mask, at the time of injury.

Comparing the data of the 15 months immediately before the GAA's new regulations, rendering it mandatory for all players aged 18 years or under to wear a protective helmet and face mask while playing hurling with the 15 months following this, the numbers of hurling-related injuries sustained was $43(71.6 \%)$, and 17 (28.3\%) before and after implementation of this new rule, respectively. Of the 43 players injured before 1 January $2005,12(27.9 \%)$ and $31(72 \%)$ were aged 18 years or under and 19 years or over, respectively. Of the 17 players who sustained hurling-related eye injuries between 1 January 2005 and 30 March 2006, two (11\%) and $15(88 \%)$ were aged 18 years or under and 19 years or older, respectively. These figures represent a significant reduction in the number of hurling-related ocular injuries sustained in players aged 18 years or under following implementation of the new rules (1 October 2003 to 31 December 2004: 12; 1 January 2005 to 30 March 2006: 2; $\chi^{2}$ test $P<0.05$ ).

However, and in the interest of statistical validity, we then compared the incidence of hurling-related ocular injuries in players aged 18 years or under in the 12-month period immediately preceding the new rules with the 12-month period immediately following the new rules, and confirmed that there was a statistically significant reduction in the incidence of hurling-related ocular injury in this age group as a result of the new rule (1 January 2004 to 31 December 2004: 11; 1 January 2005 to 31 December 2005: 2; $\chi^{2}$ test $P<0.05$ ). The $95 \%$ CI for this difference is $1.93-16.07$.

Twenty-one (35\%) players were wearing some sort of protective helmet, with or without a face mask, at the time of ocular injury. Of these, $13(61.9 \%)$ presented before implementation of the new rule and eight (38\%) presented after implementation of the new rule. Four (33.3\%) of the 12 injuries sustained while wearing eye protection before implementation of the new rule were aged 18 years or under, and this compares with two $(100 \%)$ of the players in this age group who presented after implementation of the new rule.

Sixteen (26.6\%) hurling-related ocular injuries during this study period warranted hospitalisation. The average length of stay $( \pm \mathrm{SD})$ was $2.75( \pm 1.1)$ days, and nine patients were brought to the operating theatre for a variety of surgical interventions, and these included: cataract removal (two); canalicular repair (two); scleral buckle for retinal dialysis (one); repair of macular hole (one); repair of lid laceration (three). The ocular injuries sustained during this study period among players aged 18 years or under are given in Figure 1.

Of the 60 hurling-related ocular injuries sustained during the study period, $11(18.3 \%)$ resulted in a 


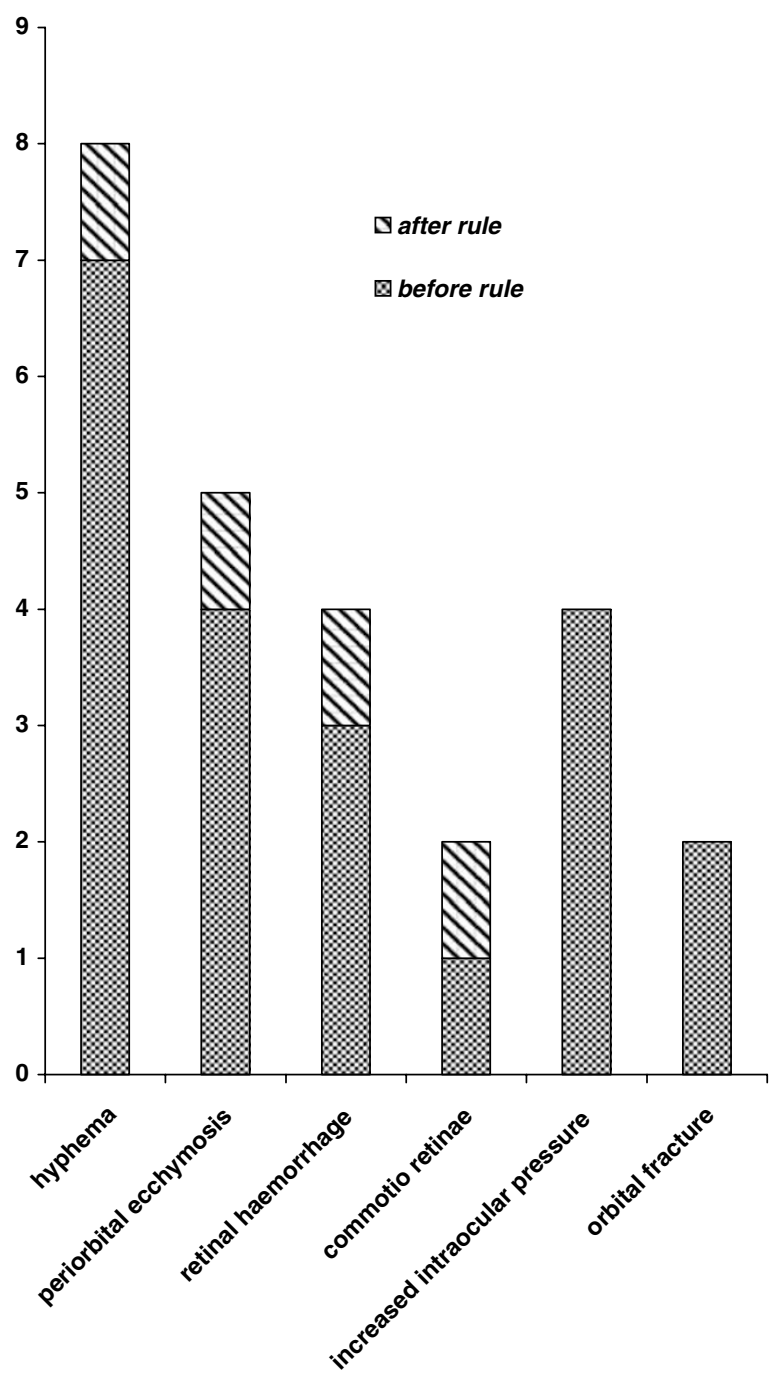

Figure 1 Nature of ocular injuries sustained among players aged 18 years or under while playing hurling before and after implementation of the new rules rendering the use of protective eye wear compulsory for players in this age group.

permanent visual deficit (Table 1). Of these, 10 (90.9\%) and one (9\%) were sustained during the 15 months immediately before and the 15 months immediately after the 1 January 2005, respectively. And, again, restricting our data analysis to those players directly affected by the new rule (ie those aged 18 years or under), one (9\%) and zero $(0 \%)$ sustained hurling-related ocular injury before and after the use of protective eye wear was made compulsory for this age group, respectively.

\section{Discussion}

This is the first study to prospectively evaluate the effect of new GAA regulations rendering the use of protective
Table 1 Visual outcomes of the 60 hurling-related ocular injuries

\begin{tabular}{lcc}
\hline Final BCVA & Before rule & After rule \\
\hline $6 / 4-6 / 12$ & 32 & 16 \\
$6 / 15-6 / 60$ & 4 & 0 \\
$<6 / 60$ & 6 & 1 \\
Unknown & 1 & 0 \\
Total & 43 & 17 \\
\hline
\end{tabular}

A permanent visual defect of $<6 / 12$ was seen in $10(23.2 \%)$ eyes before 1 January 2005 , whereas only one (5.8\%) was seen following introduction of new rule rendering the use of protective helmets and face masks compulsory for players aged 18 years or under. Only one player aged 18 years or under sustained permanent visual defect as a result of injury during the study period, and this was before the introduction of new rules rendering it compulsory for players in this age group to wear protective eye wear.

helmets and face masks compulsory for players aged 18 years or under. Hurling-related eye injuries have long been recognized as an important cause of ocular morbidity in Ireland, and it is estimated that $90 \%$ of hurling-related eye injuries are preventable. ${ }^{4}$ This is consistent with the successful campaign of the Canadian Ophthalmologist Society, which encouraged the Canadian Amateur Hockey Association to render the use of protective facemasks compulsory in 1974, and this measure resulted in a dramatic decrease in eye injuries among hockey players. ${ }^{5,6}$

As a result of data published in the British Journal of Sports Medicine in 2005, the GAA passed a motion which has made it mandatory for players aged 18 years or under to wear helmets and face guards while playing hurling. This new rule came into effect from 1 January 2005.

This study demonstrates that the overall incidence of hurling-related eye injuries has reduced following implementation of new rules rendering it mandatory for players aged 18 years or under to wear protective eye wear, and especially for those players in the age group directly affected by this rule. Ocular injuries with permanent visual sequelae were also less common following introduction of the new rule, and, again, especially for those players aged 18 years or under.

Flynn $e \mathrm{al}^{3}$ reported that impairment of vision and discomfort were the reasons most commonly cited by players for not using protective helmets and face masks while engaged in hurling. We cannot comment meaningfully on the compliance with new regulations rendering the use of protective helmets and face masks compulsory amongst hurlers, because our study is inheritably biased in this respect because the data was collected in the A\&E section, and therefore reports only those players who did sustain ocular injuries while playing this game. Nevertheless, it is noteworthy that all 
extended to players aged 21 years or under from 1 April 2006. Ultimately, however, all players should wear protective helmets and face masks while playing this wonderful game.

\section{References}

1 Watson AWS. Sports injuries in the game of hurling. Am J Sports Med 1996; 24: 323-328.

2 King SJ. http://en.wikipedia.org/wiki/Hurling. Wikimedia Foundation Inc.: Wikipedia, 2006.

3 Flynn TH, Fennessy K, Horgan N, Walsh B, O'Connell E, Cleary P et al. Ocular injury in hurling. Brit J Sport Med 2005; 39: 493-496.

4 Vinger PF. Sports related eye injury, a preventable problem. Surv Ophthalmol 1980; 25: 47-51.

5 Pashby TJ, Pashby RC, Chisholm LDJ, Crawford JS. Eye injuries in Canadian hockey. Can Med Assoc J 1975; 113: 663-664 +674.

6 Pashby TJ. Eye injuries in Canadian hockey. Phase III: older players now most at risk. Can Med Assoc J 1979; 121: 643-644. or under, in terms of the incidence and severity of ocular injuries, we are pleased to see that this rule has now been

those players aged 18 years or under who sustained a blindness, and many more cases of partial sightedness/ year in Ireland.

Given the beneficial effect of rendering the use of protective eye wear mandatory for players aged 18 years 